\title{
Comparison of noise redistribution in an SOA in pass-through and wavelength conversion mode
}

\author{
Öhman, Filip; Tromborg, Bjarne; Mørk, Jesper
}

Published in:

2004 IEEE LEOS Annual Meeting, Conference Proceedings

Link to article, DOI:

10.1109/LEOS.2004.1363277

Publication date:

2004

Document Version

Publisher's PDF, also known as Version of record

Link back to DTU Orbit

Citation (APA):

Öhman, F., Tromborg, B., \& Mørk, J. (2004). Comparison of noise redistribution in an SOA in pass-through and wavelength conversion mode. In 2004 IEEE LEOS Annual Meeting, Conference Proceedings (pp. 394-395). IEEE. https://doi.org/10.1109/LEOS.2004.1363277

\section{General rights}

Copyright and moral rights for the publications made accessible in the public portal are retained by the authors and/or other copyright owners and it is a condition of accessing publications that users recognise and abide by the legal requirements associated with these rights.

- Users may download and print one copy of any publication from the public portal for the purpose of private study or research.

- You may not further distribute the material or use it for any profit-making activity or commercial gain

- You may freely distribute the URL identifying the publication in the public portal 


\title{
Comparison of noise redistribution in an SOA in pass-through and wavelength conversion mode
}

\author{
Filip Öhman, Bjarne Tromborg and Jesper Mørk \\ Research Center COM, Technical University of Denmark, Build. 345v, DK-2800 Kgs. Lyngby, Denmark \\ fo@com.dtu.dk
}

\begin{abstract}
We use numerical simulations to investigate the redistribution of noise in a saturated SOA. A comparison of cross-gain modulation and self-modulation pass-through modes shows fundamental differences relevant to all-optical wavelength converters and regenerators.
\end{abstract}

\section{Introduction}

Realisation of transparent optical networks requires that a number of signal processing operations, today made in the electrical domain, can be done all-optically with acceptable noise performance. In non-linear devices for all-optical signal processing such as wavelength converters and regenerators, the performance depends on both the noise added by the device and the redistribution of the input noise. Since many of these devices are based on saturation effects in semiconductor optical amplifiers (SOAs), their noise properties are relevant to investigate in detail. The noise properties of cross-gain modulation (XGM) in SOAs have been investigated in [1-4] and the noise redistribution in pass-through mode in $[5,6]$. In this work we compare the XGM and pass-through modes by studying noise distributions and the interplay between input noise and added amplified spontaneous emission noise.

\section{The concept and numerical model}

We consider an SOA with two input channels, signal 1 and signal 2. In the XGM case we assume the input noise in signal 1 to be dominant, and study how it is transferred to signal 2. In the pass-through case we assume that the dominant input noise is on signal 2 . In both cases we examine signal 2 at the output.

The SOA model is a rate equation model including co-propagating amplified spontaneous emission noise through Langevin noise terms. The model is derived from references $[7,8]$, and more details on similar simulations can be found in reference [9]. The output signal is detected using an ideal noiseless detector and the resulting electrical signal is filtered in order to simulate a limited detection bandwidth. The detected signal is characterized using statistical central moments in order to quantify the degree of noise redistribution. The two measures used are the standard deviation (derived from the second order central moment) and the skewness (derived from the third order central moment) [10]. The skewness describes the asymmetry of the probability density function, PDF, of the signal with a positive/negative number indicating a long high/low signal tail.

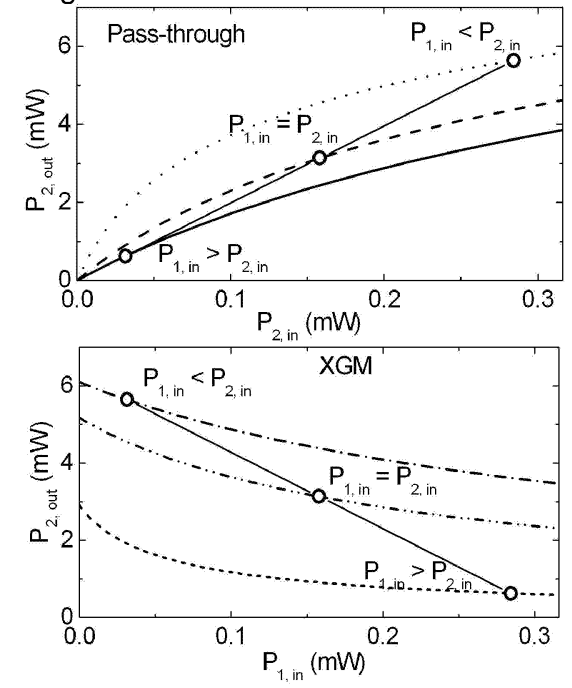

Fig. 1. Transfer functions of the pass-through (top) and XGM (bottom). The three chosen operating points are shown as circles.

\section{Results}

All the simulations are performed at a total input power of $-5 \mathrm{dBm}$, where the gain is saturated and equal to 13 $\mathrm{dB}$. We consider three different relative input powers of the two signals, $P_{1, i n}=9 P_{2, i n}, \quad P_{1, i n}=P_{2, i n}, P_{2, i n}=9 P_{1, i n}$. These operating points are shown in figure 1, together with the intensity transfer functions for the two cases. In each case the three transfer curves are for fixed input signals $P_{1, \text { in }}$ (pass-through) or $P_{2, \text { in }}$ (XGM) given by the operating points. The output $3 \mathrm{~dB}$ saturation power is about $0 \mathrm{dBm}$. Both signals are $\mathrm{CW}$. The input signal to noise ratio of the noisy signal is $15 \mathrm{~dB}$ at a detection bandwidth of $10 \mathrm{GHz}$.

The noise compression in an SOA due to gain modulation is well understood for both XGM $[3,4]$ and pass-through $[5,6]$. Figure 2 shows the output standard deviation normalised with the standard deviation at the input, for the same detection bandwidth, and with the saturated gain. The noise suppression due to the low 
slope of the transfer functions (see Fig. 1) is seen for both cases. For the XGM this means that a high $P_{1}$ results in larger noise suppression, while for the passthrough case a larger suppression is achieved for large $P_{2}$. Furthermore the different bandwidth dependence of the two cases, low-pass for XGM and high-pass for pass-through, is seen. For the XGM case an interesting interplay between the transferred noise and added ASE is seen when the same simulation but without ASE is plotted. The high-pass characteristic of the ASE from the saturated SOA [5] counteracts the low-pass characteristic of the transferred noise and results in a fairly constant standard deviation with detection bandwidth. The large relative influence of the ASE in the low $P_{1}$ case is due to the small input noise connected to the input power through the constant signal to noise ratio.

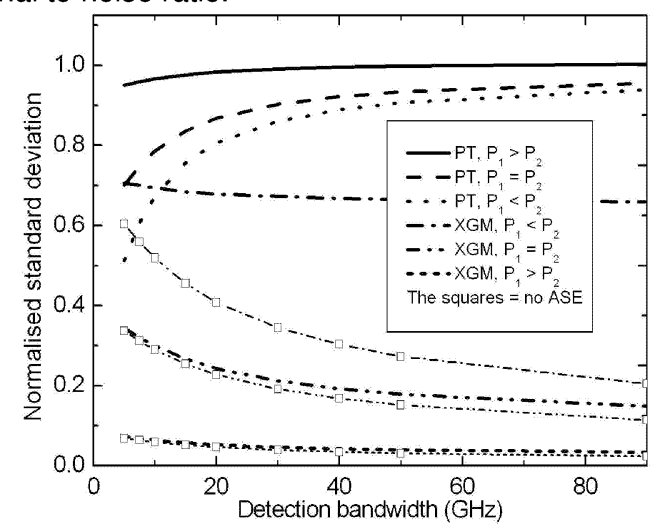

Fig. 2. Standard deviation normalised with the input standard deviation and the saturated gain of the amplifier, for both pass-through and wavelength conversion.

The skewness of the two cases is shown in figure 3 . For the pass-through case there is a shift towards smaller skewness for all operating points, in accordance with [6] and what is expected from the curvature of the non-linear static transfer function. In the XGM case, however the situation is a bit more complex. The input intensity noise has a non-central $\chi^{2}$ distribution, in accordance with Gaussian noise in the optical field. This distribution always has a positive skewness and when it is transferred through the XGM the high power side of the input distribution becomes the low power side of the output distribution, and hence the distribution is mirrored and the output skewness becomes negative. This effect can be seen for the low $P_{1}$ case in figure 3 (right side), although the effect is again hidden by the added ASE noise, which is noncentral $\chi^{2}$-distributed and has a high-pass characteristic. For higher $P_{1}$ the curvature of the transfer function redistributes the noise in the opposite direction compared to the pass-through case and the skewness becomes even more positive.

These noise redistributions are relevant to bit error rate, BER, estimations in a communication system since the BER is evaluated in the tails of the probability distributions where the redistribution due to non-linear transfer functions is large. In both the pass-through and XGM cases the redistribution skews the distribution in a direction that counteracts the improvement in SNR expected from the suppression of the standard deviation of the noise.

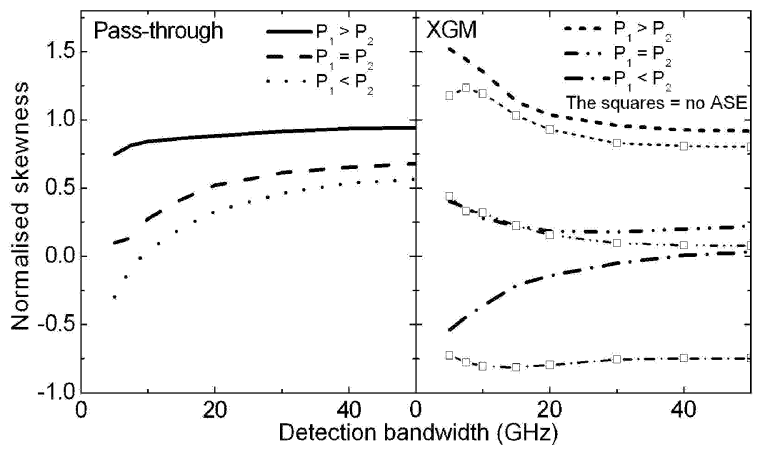

Fig. 3. Skewness normalised with the input skewness for the pass-through and XGM case.

\section{Conclusions}

The non-linear redistribution of noise in pass-through and $X G M$ in a saturated SOA is shown to not only suppress the noise but also distort the noise distribution such that the potential improvement in signal quality due to the noise suppression is counteracted. This has important consequences for all-optical regenerators and wavelength converters.

\section{References}

[1] K. Obermann et al., IEE Proc. Optoelectron. Vol. 147, 133-137, (2000)

[2] M. Muñoz et al. J. Lightwave Tech. Vol. 21, 182197 (2003)

[3] S. Wu et al. J. Opt. Commun. Vol. 23, 91-94, (2002)

[4] K, Inoue IEEE Photon. Tech. Lett. Vol 8, 888-890, (1996)

[5] M. Shtaif et al. IEEE J. Quantum Electron. Vol 34, 869-878, (1997)

[6] F. Öhman et al. Proc. CLEO 2004, CtuP5, (2004)

[7] D. Marcenac et al. IEEE Photon. Tech. Lett. Vol.9, 749-751, (1997)

[8] D. Cassioli et al. IEEE J. Quatum Electron. Vol. 36, 1072-1080, (2000)

[9] F. Öhman et al. IEEE J. Quatum Electron. Vol. 40, 245-255, (2004)

[10] B. Saleh, Photoelectron Statistics, (SpringerVerlag, New York, 1978), Chap. 2. 